\title{
Unimodal relationship between small-scale barnacle recruitment and the density of pre-existing barnacle adults (\#17214)
}

First revision

Please read the Important notes below, the Review guidance on page 2 and our Standout reviewing tips on page 3 . When ready submit online. The manuscript starts on page 4.

Important notes

\section{Editor}

Donald Kramer

Files

1 Tracked changes manuscript(s)

1 Rebuttal letter(s)

2 Figure file(s)

1 Table file(s)

1 Raw data file(s)

Please visit the overview page to download and review the files not included in this review PDF.

Declarations

No notable declarations are present 
Please read in full before you begin

\section{How to review}

When ready submit your review online. The review form is divided into 5 sections. Please consider these when composing your review:

\section{BASIC REPORTING}

2. EXPERIMENTAL DESIGN

3. VALIDITY OF THE FINDINGS

4. General comments

5. Confidential notes to the editor

You can also annotate this PDF and upload it as part of your review

To finish, enter your editorial recommendation (accept, revise or reject) and submit.

\section{BASIC REPORTING}

Clear, unambiguous, professional English language used throughout.

Intro \& background to show context. Literature well referenced $\&$ relevant.

Structure conforms to PeerJ standards, discipline norm, or improved for clarity.

Figures are relevant, high quality, well labelled \& described.

Raw data supplied (see PeerJ policy).

\section{EXPERIMENTAL DESIGN}

Original primary research within Scope of the journal.

Research question well defined, relevant $\&$ meaningful. It is stated how the research fills an identified knowledge gap.

Rigorous investigation performed to a high technical \& ethical standard.

Methods described with sufficient detail \& information to replicate.

\section{VALIDITY OF THE FINDINGS}

Impact and novelty not assessed. Negative/inconclusive results accepted. Meaningful replication encouraged where rationale $\&$ benefit to literature is clearly stated.

Data is robust, statistically sound, $\&$ controlled.
Conclusions are well stated, linked to original research question \& limited to supporting results.

Speculation is welcome, but should be identified as such.

The above is the editorial criteria summary. To view in full visit https://peerj.com/about/editorialcriteria/ 
The best reviewers use these techniques

Tip

\author{
Support criticisms with \\ evidence from the text or from \\ other sources
}

\section{Give specific suggestions on how to improve the manuscript}

\section{Comment on language and grammar issues}

Organize by importance of the issues, and number your points

\section{Example}

Smith et al (J of Methodology, 2005, V3, pp 123) have shown that the analysis you use in Lines 241-250 is not the most appropriate for this situation. Please explain why you used this method.

Your introduction needs more detail. I suggest that you improve the description at lines 57- 86 to provide more justification for your study (specifically, you should expand upon the knowledge gap being filled).

The English language should be improved to ensure that your international audience can clearly understand your text. I suggest that you have a native English speaking colleague review your manuscript. Some examples where the language could be improved include lines 23, 77, 121, 128 - the current phrasing makes comprehension difficult.

1. Your most important issue

2. The next most important item

3. ...

4. The least important points

Line 56: Note that experimental data on sprawling animals needs to be updated. Line 66: Please consider exchanging "modern" with "cursorial".

I thank you for providing the raw data, however your supplemental files need more descriptive metadata identifiers to be useful to future readers. Although your results are compelling, the data analysis should be improved in the following ways: $A A, B B, C C$

I commend the authors for their extensive data set, compiled over many years of detailed fieldwork. In addition, the manuscript is clearly written in professional, unambiguous language. If there is a weakness, it is in the statistical analysis (as I have noted above) which should be improved upon before Acceptance.
Comment on strengths (as well as weaknesses) of the manuscript




\title{
Unimodal relationship between small-scale barnacle recruitment and the density of pre-existing barnacle adults
}

\author{
Ricardo A Scrosati ${ }^{\text {Corresp., }}{ }^{1}$, Julius A Ellrich ${ }^{1}$ \\ ${ }^{1}$ Department of Biology, St. Francis Xavier University, Antigonish, Nova Scotia, Canada \\ Corresponding Author: Ricardo A Scrosati \\ Email address: rscrosat@stfx.ca
}

Recruitment is a key demographic process for population persistence. This paper focuses on barnacle (Semibalanus balanoides) recruitment. In rocky intertidal habitats from the Gulf of St. Lawrence coast of Nova Scotia (Canada), ice scour is common during the winter. At the onset of intertidal barnacle recruitment in early May (after sea ice has fully melted), mostly only adult barnacles and bare substrate are visible at high elevations in waveexposed habitats. We conducted a multiannual study to investigate if small-scale barnacle recruitment could be predicted from the density of pre-existing adult barnacles. In a year that exhibited a wide adult density range (ca. 0-130 individuals $\mathrm{dm}^{-2}$ ), the relationship between adult density and recruit density (scaled to the available area for recruitment, which excluded adult barnacles) was unimodal. In years that exhibited a lower adult density range (ca. 0-40/50 individuals $\mathrm{dm}^{-2}$ ), the relationship between adult and recruit density was positive and resembled the lower half of the unimodal relationship. Overall, adult barnacle density was able to explain $26-40 \%$ of the observed variation in recruit density. The unimodal adult-recruit relationship is consistent with previously documented intraspecific interactions. Between low and intermediate adult densities, the positive nature of the relationship relates to the previously documented fact that adult barnacles attract settlement-seeking larvae, which likely enhances local population persistence where it is most needed. Between intermediate and high adult densities, where population persistence may be less compromised and the abundant adults may limit recruit growth and survival, the negative nature of the relationship suggests that adult barnacles at increasingly high densities stimulate larvae to settle elsewhere. The unimodal pattern may be especially common on shores with moderate rates of larval supply to the shore, because high rates of larval supply may swamp the coast with settlers, decoupling recruit density from local adult abundance. 
1 Unimodal relationship between small-scale barnacle recruitment and the density of pre-existing barnacle adults

* Corresponding author. Email: rscrosat@stfx.ca. Phone: 1-902-867-5289 


\section{Abstract}

Recruitment is a key demographic process for population persistence. This paper focuses on barnacle (Semibalanus balanoides) recruitment. In rocky intertidal habitats from the Gulf of St.

10 Lawrence coast of Nova Scotia (Canada), ice scour is common during the winter. At the onset of 11 intertidal barnacle recruitment in early May (after sea ice has fully melted), mostly only adult

12 barnacles and bare substrate are visible at high elevations in wave-exposed habitats. We

13 conducted a multiannual study to investigate if small-scale barnacle recruitment could be

14 predicted from the density of pre-existing adult barnacles. In a year that exhibited a wide adult

15 density range (ca. $0-130$ individuals $\mathrm{dm}^{-2}$ ), the relationship between adult density and recruit

16 density (scaled to the available area for recruitment, which excluded adult barnacles) was

17 unimodal. In years that exhibited a lower adult density range (ca. 0-40/50 individuals $\mathrm{dm}^{-2}$ ), the 18 relationship between adult and recruit density was positive and resembled the lower half of the

19 unimodal relationship. Overall, adult barnacle density was able to explain $26-40 \%$ of the

20 observed variation in recruit density. The unimodal adult-recruit relationship is consistent with

21 previously documented intraspecific interactions. Between low and intermediate adult densities,

22 the positive nature of the relationship relates to the previously documented fact that adult 2

23 barnacles attract settlement-seeking larvae, which likely enhances local population persistence

24 where it is most needed. Between intermediate and high adult densities, where population

25 persistence may be less compromised and the abundant adults may limit recruit growth and

26 survival, the negative nature of the relationship suggests that adult barnacles at increasingly high

27 densities stimulate larvae to settle elsewhere. The unimodal pattern may be especially common

28 on shores with moderate rates of larval supply to the shore, because high rates of larval supply

29 may swamp the coast with settlers, decoupling recruit density from local adult abundance. 


\section{Introduction}

31 Recruitment is a key demographic process that affects the persistence of populations. Thus,

32 ecological research has often aimed at understanding its drivers (Caley et al., 1996; Beck et al.,

33 2001; Palumbi \& Pinsky, 2014). As barnacles are abundant organisms on seashores worldwide,

34 they have often been used as model systems to study recruitment (Jenkins et al., 2000; Navarrete

35 et al., 2008; Lathlean et al., 2013; Menge et al., 2015; Barbosa et al., 2016). For barnacles,

36 settlement refers to the permanent contact with the substrate established by pelagic larvae

37 (Jenkins et al., 2000), while recruitment is the appearance of new organisms in a benthic habitat

38 that have resulted from the metamorphosis of settled larvae (Ellrich et al., 2016a). At regional

39 spatial scales, common drivers of barnacle recruitment are seawater temperature and pelagic

40 food (phytoplankton) supply, as both factors influence the growth and survival of the pelagic

41 larvae (Menge \& Menge, 2013; Rognstad et al., 2014; Scrosati \& Ellrich, 2016). At small spatial

42 scales, factors such as substrate rugosity (Coombes et al. 2015), water motion (Bertness et al.,

43 1992; Ellrich \& Scrosati, 2016), macroalgal canopies (Beermann et al., 2013), and predator

44 chemical cues (Johnson \& Strathmann, 1989; Ellrich et al., 2015) influence barnacle recruitment

45 in a variety of ways.

46 The presence of benthic conspecifics also influences barnacle recruitment at small scales.

47 For instance, experiments conducted under laboratory (Crisp \& Meadows, 1962; Matsumura et

48 al., 2000; Matsumura \& Qian, 2014) and field (Chabot \& Bourget, 1988; Raimondi, 1988;

49 Jarrett, 1997) conditions have shown that chemical and visual cues from adult barnacles attract

50 pelagic conspecific larvae that are seeking settlement. Such an attraction is believed to aid larvae

51 to locate adequate areas for growth and reproduction (Clare, 2011). In agreement with those

52 findings, field experiments found that the presence of adult barnacles in moderate densities 
53 enhance barnacle recruitment at small spatial scales (Bertness et al., 1992; Kent et al., 2003;

54 Beermann et al., 2013; Ellrich et al., 2016a).

55 The above studies suggest that small-scale recruitment in barnacle populations could be

56 predicted from the density of pre-existing adult barnacles. Between low and intermediate adult

57 densities, larval attraction by conspecific adults should result in a positive relationship between

58 adult and recruit density. However, between intermediate and high adult densities, the abundant

59 conspecific cues might indicate to pelagic larvae the potential for detrimental intraspecific

60 interactions, as the resulting recruits might be crushed by growing adults or experience a reduced

61 food supply outcompeted by the abundant adults (Bertness et al., 1998; Hooper \& Eichhorn,

62 2016). In such conditions, recruit density (scaled to the substrate area available for settlement)

63 could decrease with adult density because of larval repulsion. Therefore, for a wide range of

64 adult density spanning low to high values, the adult-recruit relationship might be unimodal. This

65 paper tests this hypothesis using field data from rocky intertidal habitats from Atlantic Canada.

\section{Materials and methods}

We measured barnacle adult and recruit density at Sea Spray $\left(45^{\circ} 46.4^{\prime} \mathrm{N}, 62^{\circ} 8.7^{\prime} \mathrm{W}\right)$, on

68 the southern coast of the Gulf of St. Lawrence, Nova Scotia. This is a long-term reference

69 location where we have monitored barnacles for several years (Scrosati \& Ellrich, 2016). We

70 surveyed habitats that face open waters, which makes these habitats wave-exposed, with daily

71 values of maximum water velocity ranging between $4-8 \mathrm{~m} \mathrm{~s}^{-1}$ (Scrosati \& Heaven, 2007). The

72 substrate is volcanic bedrock with a homogeneous rugosity and slope. On this coast,

73 Semibalanus balanoides is the only species of intertidal barnacle (Scrosati \& Heaven, 2007). In

74 Atlantic Canada, this species mates in autumn, broods in winter, and releases larvae to the water

75 column in spring (Bousfield, 1954; Crisp, 1968; Bouchard \& Aiken, 2012). On the studied coast, 
76 recruits of S. balanoides appear in May and June (Ellrich et al., 2015) along the full vertical

77 intertidal range (MacPherson \& Scrosati, 2008; MacPherson et al., 2008). The recruited

78 organisms reach reproductive maturity and adult size in the following fall (Ellrich et al., 2016b).

79 In winter, the sea surface of the Gulf of St. Lawrence freezes extensively (Galbraith et al., 2015)

80 and the ice causes physical disturbance in intertidal habitats as it moves with tides, winds,

81 currents, and waves (Scrosati \& Heaven, 2006; Musetta-Lambert et al., 2015). The ice melts

82 before barnacle recruitment begins. As a result of ice scour, the macroscopic organisms

83 occurring in high-intertidal habitats facing open waters (habitats where winter ice scour is

84 intense) just before barnacle recruitment are almost exclusively adult barnacles scattered across

85 otherwise bare rocky substrate. Benthic macroalgae and mobile consumers (e.g., snails) remain

86 virtually absent in such places during the barnacle recruitment season. Those organisms begin to

87 appear at such elevations mostly after barnacle recruits have ceased to appear (Scrosati \&

88 Heaven, 2007). Thus, no interspecific interactions seemingly influence barnacle recruitment in

89 those habitats, leaving adult barnacle density as an important potential predictor of barnacle

90 recruitment.

91 We measured barnacle adult and recruit density at the lower part of the high intertidal zone,

92 at an elevation of approximately $1.2 \mathrm{~m}$ above chart datum (lowest normal tide). During the

93 second or third week of June between 2007 and 2016, we took digital pictures of 29-33

94 (depending on the year) $10 \mathrm{~cm} \mathrm{x} 10 \mathrm{~cm}$ quadrats randomly positioned at that elevation spanning

$9520 \mathrm{~m}$ of coastline. With this approach, we were able to remove the influence of large-scale

96 oceanographic factors on larval and recruit ecology (Menge \& Menge, 2013) and, thus, to focus

97 on small-scale influences at the patch (quadrat) level. We used the pictures of the quadrats to

98 measure adult and recruit density on a computer. In June, barnacle recruits are easily 
99 distinguished from adults, because recruits are only 1-2 $\mathrm{mm}$ in basal diameter (Fig. 1). Barnacle

100 recruits were always abundant in the studied years (Scrosati \& Ellrich, 2016), but adult barnacles

101 were often absent in the quadrats between 2010 and 2016, preventing us from considering those

102 years to meaningfully test our hypothesis. Therefore, we evaluated the hypothesis of this study

103 using the datasets for 2007, 2008, and 2009.

104 For each quadrat, we calculated barnacle adult density by dividing the number of adult

105 barnacles found therein by quadrat area $\left(1 \mathrm{dm}^{2}\right)$. To calculate recruit density, we divided the

106 number of recruits found in a quadrat by the area that was available for larvae to settle (and, thus,

107 for recruits to occur), which was quadrat area minus the area covered by adult barnacles because<smiles>C1=CC=C1</smiles>

108 larvae did not settle on the shells of adult barnacles. Under this analytical approach, if barnacle

109 adults had no ecological effect on larval settlement and subsequent recruitment, there would be

110 no relationship between adult density and recruit density (standardized as indicated above). A

111 positive relationship would indicate attraction of larvae by adults, while a negative relationship

112 would indicate repulsion of larvae by adults.

113 We tested our hypothesis by analyzing the 2007, 2008, and 2009 datasets separately. For

114 each year, we fitted the data to a linear model, a power model, and a quadratic model,

115 considering adult barnacle density as the independent variable and recruit density as the

116 dependent variable. Then, we compared the three models using an information-theoretic

117 approach. We considered linear and power models to evaluate potentially positive adult-recruit

118 relationships. While a linear model would describe a constant rate of change of recruit density

119 along the observed gradient of adult density, a power model would allow that rate to vary along

120 that gradient, potentially making the model more realistic. We considered a quadratic model to

121 evaluate the potential unimodal nature of the adult-recruit relationship. All models included an 
122 intercept to acknowledge the possibility that recruit density could have non-zero values in the

123 absence of adult barnacles. The models were: $N_{R}=\mathrm{a} N_{A}+\mathrm{b}$ (linear), $N_{R}=\mathrm{a} N_{A}{ }^{\mathrm{b}}+\mathrm{c}$ (power), and

$124 N_{R}=\mathrm{a} N_{A}^{2}+\mathrm{b} N_{A}+\mathrm{c}$ (quadratic), where $N_{R}$ is recruit density and $N_{A}$ is adult density.

125 For each year, we compared the models based on their values of the corrected Akaike's

126 information criterion (AICc). With such values, we calculated the weight of evidence for each

127 model, which we used to identify the best model (the one with the highest weight of evidence)

128 for each year. Then, for each year, we evaluated the plausibility of the best model relative to the

129 two least favoured ones by calculating the corresponding evidence ratios between the weight of

130 evidence for the best model and the weight of evidence for the two least supported models

131 (Anderson, 2008). We calculated the adjusted squared correlation coefficient $\left(R^{2}\right)$ for all models

132 to determine the amount of variation in recruit density that was statistically explained by adult

133 density (Sokal \& Rohlf, 2012). We conducted these analyses with PRISM 6.0c for MacOS.

$134 \quad$ Results

135 In 2007 and 2009, adult barnacle density at the quadrat scale was never higher than 46

136 individuals $\mathrm{dm}^{-2}$, while barnacle recruits occurred abundantly in all quadrats (Fig. 2). For both

137 years, the best model describing the adult-recruit relationship was the power model (Table 1).

138 For 2007, the power model was 1.8 times more plausible than the linear model and 4.3 times

139 more plausible than the quadratic model while, for 2009, it was 1.9 times more plausible than the

140 linear model and 3.5 times more plausible than the quadratic model (Table 1). The power model

141 also explained a higher percentage of the observed variation in recruit density (31\% in 2007 and

$14226 \%$ in 2009) than the other two models (Table 1).

143 In 2008, adult barnacle density exhibited a wider range than in 2007 and 2009. The highest

144 value found in 2008 (129 individuals $\mathrm{dm}^{-2}$ ) was almost three times higher than the highest value 
145 found for the other two years. In 2008, barnacle recruits were also abundant on the shore (Fig. 2).

146 The best model describing the adult-recruit relationship in 2008 was the quadratic one, which

147 was 4.1 times more plausible than the power model and 14.2 times more plausible than the linear

148 one (Table 1). For 2008, the quadratic model explained a higher percentage of the observed

149 variation in recruit density (40\%) than the other two models (Table 1).

\section{Discussion}

By monitoring a natural barnacle population spanning a wide range of adult density (in

152 2008), the predicted unimodal adult-recruit relationship was supported. When the available

153 range of adult density covered only low to intermediate values (in 2007 and 2009), a positive

154 relationship resembling the lower half of the unimodal relationship was found. This is a valuable

155 outcome for two reasons. The first one is that this study provides an example of how the shape of

156 a natural trend can be predicted from experiments that evaluated intraspecific interactions under

157 different densities of adult barnacles separately, either under moderate densities (Raimondi,

158 1988; Kent et al., 2003; Beermann et al., 2013; Ellrich et al., 2016a) or high densities (Bertness

159 et al., 1998; Hooper \& Eichhorn, 2016). The second reason is that local-scale recruitment, a key

160 driver of population persistence for sessile invertebrates (Minchinton \& Scheibling, 1993;

161 Lathlean et al., 2013), is hereby shown to be linked to the abundance of adult conspecifics. At

162 small spatial scales, adult barnacles generally do not contribute to local population persistence

163 through the larvae they spawn, because pelagic larvae are taken elsewhere by water motion

164 (Caley et al., 1996). However, the fact that adult barnacles attract settlement-seeking larvae

165 (regardless of where larvae come from) determines a ngsitive adult-recruit relationship for

166 moderate adult densities, which likely enhances local population persistence where it is most

167 needed. Habitat areas with higher adult densities, where population persistence may be less 
168 compromised and the abundant adults may hinder recruit growth and survival, seem to stimulate

169 larvae to settle elsewhere.

170 Using observed patterns of recruit density to infer patterns of larval settlement requires the

171 assumption that post-settlement mortality until recruit counts are done is unimportant. This was

172 seemingly the case for our system, because empty recruit shells (indicative of recruit mortality)

173 were very rare at the time of our surveys (see, for example, Fig. 1). Mortality becomes important

174 only later in the year, especially as the growing organisms experience thermal and desiccation

175 stress during the summer low tides.

176 It is worth noting that an observational study done on the coast of New Brunswick, also in

177 Atlantic Canada, reported a unimodal relationship for Semibalanus balanoides between recruit

178 density and the percent cover of pre-existing adults (Chabot \& Bourget, 1988). However, that

179 study scaled recruit density to quadrat area. Given that larvae were noted (as in our study) to

180 avoid settling on adults, that study suggested that recruit density decreased from intermediate to

181 high values of adult cover because of the decreasing area available for larval settlement (Chabot

$182 \&$ Bourget, 1988). As we scaled recruit density to the available area for

183 excludes adult barnacles), the present study in fact reveals that repulsion of settling larvae by

184 adults operates from intermediate to high values of adult abundance.

185 Immigration also represents the arrival of new organisms to a place, although it differs from 186 recruitment because immigrants are normally actively moving juveniles and adults, not recruits.

187 Thus, it is worth noting that a recent study using damselfish has experimentally demonstrated a

188 unimodal relationship between local fish density and the density of conspecific immigrants

189 (Turgeon \& Kramer, 2016). The reasons for such a pattern seem also related to conspecific 
190 attraction at moderate densities and the potential for competitive interactions at high densities

191 (Turgeon \& Kramer, 2016).

192 The unimodal adult-recruit relationship for barnacles would likely hold mainly on shores

193 where the supply of pelagic larvae to intertidal habitats is moderate. On shores subjected to a

194 very high larval supply (e.g., because of mild water temperatures or high planktonic food

195 supply), larvae quickly colonize preferred substrate and new larvae arriving to the shore

196 eventually colonize less preferred areas also abundantly (Bertness et al., 1992). This suggests

197 that, under very high larval supply rates, barnacle recruit density could be unrelated to the

198 density of pre-existing adults. Seemingly in support of this notion, a study on Scottish shores

199 subjected to an unusually high supply of S. balanoides larvae reported no linear relationship

200 between the density of recruits and that of pre-existing adults (Hansson et al., 2003). However,

201 the possible occurrence of nonlinear relationships was not evaluated in that study. In addition,

202 the data examined in that study included density values from several intertidal elevations, which

203 likely increased data variability because larval settlement rates increase towards lower elevations

204 because of the longer immersion times (Bertness et al., 1992). It would thus appear useful to

205 apply the methodology of the present study to evaluate on a suitable shore the notion that

206 barnacle recruit density is unrelated to the density of pre-existing adults under very high rates of

207 larval supply.

208 Finally, despite the variety of factors that influence barnacle recruitment at small scales

209 (Johnson \& Strathmann, 1989; Bertness et al., 1992; Beermann et al., 2013; Coombes et al.

210 2015; Ellrich et al., 2015; Ellrich \& Scrosati, 2016), it is remarkable that a single factor (adult

211 barnacle density) was able to explain $26-40 \%$ of the variation in recruit density observed on our

212 shore. This may have been the case because the surveyed habitats exhibit a similar degree of 
213 wave exposure and substrate rugosity, composition, and slope. This was, in fact, the main reason

214 to select this coast to address the objective of this study. In any case, a multifactorial field

215 experiment could evaluate the relative explanatory ability of several small-scale factors acting

216 simultaneously. This would be a profitable exercise, as the majority of studies have generally

217 evaluated the influence of only one or two factors at a time (Johnson \& Strathmann, 1989;

218 Beermann et al., 2013; Coombes et al., 2015; Ellrich et al., 2015; Ellrich \& Scrosati, 2016).

219 Acknowledgements We thank Donald Kramer, Augusto Flores, and an anonymous

220 reviewer for constructive comments on an earlier version of this paper.

$221 \quad$ References

222 Anderson DR. 2008. Model-based inference in the life sciences: a primer on evidence. New

223 York: Springer.

224 Barbosa ACC, Gomes CC, Pereira GC, Bueno M, Flores AAV. 2016. Local biological

225 drivers, not remote forcing, predict settlement rate to a subtropical barnacle population. Marine

226 Ecology Progress Series 543:201-208.

227 Beck MW, Heck KL, Able KW, Childers DL, Eggleston DB, Gillanders BM, Halpern B,

228 Hays CG, Hoshino K, Minello TJ, Orth RJ, Sheridan PF, Weinstein MP. 2001. The

229 identification, conservation, and management of estuarine and marine nurseries for fish and

230 invertebrates. BioScience 51:633-641.

231 Beermann AJ, Ellrich JA, Molis M, Scrosati RA. 2013. Effects of seaweed canopies and adult

232 barnacles on barnacle recruitment: the interplay of positive and negative influences. Journal of 233 Experimental Marine Biology and Ecology 448:162-170. 
234 Bertness MD, Gaines SD, Stephens EG, Yund PO. 1992. Components of recruitment in

235 populations of the acorn barnacle Semibalanus balanoides (Linnaeus). Journal of Experimental

236 Marine Biology and Ecology 156:199-215.

237 Bertness MD, Gaines SD, Yeh SM. 1998. Making mountains out of barnacles: the dynamics of 238 acorn barnacle hummocking. Ecology 79:1382-1394.

239 Bouchard GM, Aiken RB. 2012. Latitudinal variation in the reproductive cycle and size of the

240 northern rock barnacle Semibalanus balanoides (L.) (Cirripedia, Archaeobalanidae) in the Bay

241 of Fundy. Crustaceana 85:779-787.

242 Bousfield EL. 1954. The distribution and spawning seasons of barnacles on the Atlantic coast of

243 Canada. Bulletin of the National Museum of Canada 132:112-154.

244 Caley MJ, Carr MH, Hixon MA, Hughes TP, Jones GP, Menge BA. 1996. Recruitment and

245 the local dynamics of open marine populations. Annual Review of Ecology and Systematics

$246 \quad 27: 477-500$.

247 Chabot R, Bourget E. 1988. Influence of substratum heterogeneity and settled barnacle density

248 on the settlement of cypris larvae. Marine Biology 97:45-56.

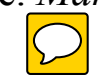

249 Clare AS. 2011. Toward a charaterization of the chemical cue to barnacle gregariousness. In:

250 Breithaupt T, Thiel M, eds. Chemical communication in crustaceans. New York: Springer, $251 \quad 431-450$.

252 Coombes MA, La Marca EC, Naylor LA, Thompson RC. 2015. Getting into the groove:

253 Opportunities to enhance the ecological value of hard coastal infrastructure using fine-scale 254 surface textures. Ecological Engineering 77:314-323. 
255 Crisp DJ. 1968. Differences between North American and European populations of Balanus

256 balanoides revealed by transplantation. Fisheries Research Board of Canada 25:2633-2641.

257 Crisp DJ, Meadows PS. 1962. The chemical basis of gregariousness in cirripedes. Proceedings

258 of the Royal Society of London B 156:500-520.

259 Ellrich JA, Scrosati RA. 2016. Water motion modulates predator nonconsumptive limitation of 260 prey recruitment. Ecosphere 7:e01402.

261 Ellrich JA, Scrosati RA, Molis M. 2015. Predator nonconsumptive effects on prey recruitment

262 weaken with recruit density. Ecology 96:611-616.

263 Ellrich JA, Scrosati RA, Romoth K, Molis M. 2016a. Adult prey neutralizes predator

264 nonconsumptive limitation of prey recruitment. PLOS ONE 11:e0154572.

265 Ellrich JA, Scrosati RA, Bertolini C, Molis M. 2016b. A predator has nonconsumptive effects 266 on different life-history stages of a prey. Marine Biology 163:5.

267 Galbraith PS, Larouche P, Chassé J, Petrie P. 2012. Sea-surface temperature in relation to air 268 temperature in the Gulf of St.Lawrence: interdecadal variability and long-term trends. Deep-

269 Sea Research II 77-80:10-20.

270 Hansson LJ, Hudson IR, Seddon RJ, Shaw O, Thomason JC. 2003. Massive recruitment of

271 the barnacle Semibalanus balanoides in the Clyde Sea (Scotland, UK) in the spring of 2000.

272 Journal of the Marine Biological Association of the United Kingdom 83:923-924.

273 Hooper RC, Eichhorn MP. 2016. Too close for comfort: spatial patterns in acorn barnacle 274 populations. Population Ecology 58:231-239.

275 Jarrett JN. 1997. Temporal variation in subtratum specificity of Semibalanus balanoides

276 (Linnaeus) cyprids. Journal of Experimental Marine Biology and Ecology 211:103-114. 
277 Jenkins SR, Åberg P, Cervin G, Coleman RA, Delany J, Della Santina P, Hawkins SJ,

278 LaCroix E, Myers AA, Lindegarth M, Power AM, Roberts MF, Hartnoll RG. 2000.

279 Spatial and temporal variation in settlement and recruitment of the intertidal barnacle

280 Semibalanus balanoides (L.) (Crustacea: Cirripedia) over a European scale. Journal of

281 Experimental Marine Biology and Ecology 243:209-225.

282 Johnson LE, Strathmann RR. 1989. Settling barnacle larvae avoid substrata previously

283 occupied by a mobile predator. Journal of Experimental Marine Biology and Ecology 128:87-

284103.

285 Kent A, Hawkins SJ, Doncaster CP. 2003. Population consequences of mutual attraction

286 between settling and adult barnacles. Journal of Animal Ecology 72:941-952.

287 Lathlean JA, Ayre DJ, Minchinton TE. 2013. Temperature variability at the larval scale

288 affects early survival and growth of an intertidal barnacle. Marine Ecology Progress Series $289 \quad 475: 155-166$.

290 MacPherson EA, Scrosati R. 2008. Population structure of the barnacle Semibalanus

291 balanoides (Cirripedia) across intertidal environmental stress gradients in northern Nova

292 Scotia, Canada. Crustaceana 81:725-736.

293 MacPherson EA, Scrosati R, Chareka P. 2008. Barnacle recruitment on ice-scoured shores in

294 eastern Canada. Journal of the Marine Biological Association of the United Kingdom 88:289-

295291.

296 Matsumura K, Hills JM, Thomason PO, Thomason JC, Clare AS. 2000. Discrimination at

297 settlement in barnacles: laboratory and field experiments on settlement behaviour in response to 298 settlement-inducing protein complexes. Biofouling 16:181-190. 
299 Matsumura K, Qian P-Y. 2014. Larval vision contributes to gregarious settlement in barnacles:

300 adult red fluorescence as a possible visual signal. Journal of Experimental Biology 217:743-

301750.

302 Menge BA, Menge DNL. 2013. Dynamics of coastal meta-ecosystems: the intermittent

303 upwelling hypothesis and a test in rocky intertidal regions. Ecological Monographs 83:283-

304310.

305 Menge BA, Gouhier TC, Hacker SD, Chan F, Nielsen KJ. 2015. Are meta-ecosystems

306 organized hierarchically? A model and test in rocky intertidal habitats. Ecological Monographs

$307 \quad$ 85:213-233.

308 Minchinton TE, Scheibling RE. 1993. Free space availability and larval substratum selection as

309 determinants of barnacle population structure in a developing rocky intertidal community.

310 Marine Ecology Progress Series 95:233-244.

311 Musetta-Lambert JL, Scrosati RA, Keppel EA, Barbeau MA, Skinner MA, Courtenay SC.

312 2015. Intertidal communities differ between breakwaters and natural rocky areas on ice-scoured

313 Northwest Atlantic coasts. Marine Ecology Progress Series 539:19-31.

314 Navarrete SA, Broitman BR, Menge BA. 2008. Interhemispheric comparion of recruitment to

315 intertidal communities: pattern persistence and scales of variation. Ecology 89:1308-1322.

316 Palumbi SR, Pinsky ML. 2014. Marine dispersal, ecology, and conservation. In: Bertness MD,

317 Bruno JF, Silliman BR, Stachowicz JJ, eds. Marine community ecology and conservation.

318 Sunderland: Sinauer, 57-83.

319 Raimondi PT. 1988. Settlement cues and determination of the vertical limit of an intertidal

320 barnacle. Ecology 69:400-407. 
321 Rognstad RL, Wethey DS, Hilbish TJ. 2014. Connectivity and population repatriation:

322 limitations of climate and input into the larval pool. Marine Ecology Progress Series 495:175323183.

324 Scrosati R, Heaven C. 2006. Field technique to quantify intensity of scouring by sea ice in 325 rocky intertidal habitats. Marine Ecology Progress Series 320:293-295.

326 Scrosati R, Heaven C. 2007. Spatial trends in community richness, diversity, and evenness

327 across rocky intertidal environmental stress gradients in eastern Canada. Marine Ecology

328 Progress Series 342:1-14.

329 Scrosati RA, Ellrich JA. 2016. A 12-year record of intertidal barnacle recruitment in Atlantic

330 Canada (2005-2016): relationships with sea surface temperature and phytoplankton abundance.

$331 \quad$ PeerJ 4:e2623.

332 Sokal RR, Rohlf FJ. 2012. Biometry. The principles and practice of statistics in biological

333 research. New York: W. H. Freeman.

334 Turgeon K, Kramer DL. 2016. Immigration rates during population density reduction in a coral 335 reef fish. PLOS ONE 11:e0156417. 
336 Table 1. Summary information for the models describing the adult-recruit relationship in

337 2007, 2008, and 2009: a, b, and c are the parameters of the equations described in Methods, $w$

338 is the weight of evidence for each model, and $\mathrm{n}$ is the number of surveyed quadrats.

\begin{tabular}{lccccccc}
\hline \multicolumn{1}{c}{ Model } & $\mathbf{a}$ & $\mathbf{b}$ & $\mathbf{c}$ & Adjusted $\boldsymbol{R}^{2}$ & AICc & $\boldsymbol{w}$ & Evidence ratio \\
\hline $\mathbf{2 0 0 7}(\mathrm{n}=30)$ & & & & & & & \\
Linear & 12.82 & 912.80 & - & 0.22 & 328.9 & 0.3077 & 1.8 \\
Power & 138.20 & 0.34 & 815.80 & 0.31 & 326.8 & 0.5607 & 1 \\
Quadratic & -0.34 & 25.44 & 877.90 & 0.25 & 329.7 & 0.1315 & 4.3 \\
2008 (n=29) & & & & & & & \\
Linear & 2.02 & 329.90 & - & 0.24 & 288.5 & 0.0536 & 14.2 \\
Power & 61.65 & 0.35 & 218.00 & 0.35 & 286.0 & 0.1872 & 4.1 \\
Quadratic & -0.04 & 7.65 & 228.80 & 0.40 & 283.2 & 0.7592 & 1 \\
2009 (n=32) & & & & & & & \\
Linear & 15.86 & 779.40 & - & 0.20 & 352.8 & 0.2887 & 1.9 \\
Power & 175.70 & 0.33 & 617.30 & 0.26 & 351.5 & 0.5529 & 1 \\
Quadratic & -0.49 & 31.49 & 736.10 & 0.20 & 354.0 & 0.1584 & 3.5 \\
\hline
\end{tabular}


341 Fig. 1. Typical view of a wave-exposed, high-intertidal habitat on the Gulf of St. Lawrence

342 coast of Nova Scotia in June, showing barnacle adults (a) and recruits (r). The sampling quadrat

343 is $10 \mathrm{~cm} \times 10 \mathrm{~cm}$. Photograph by R. A. Scrosati.

344 Fig. 2. Relationships between standardized barnacle recruit density (scaled to the available area

345 for recruitment in each quadrat) and the density of pre-existing adult barnacles (always scaled to

346 quadrat area) in June 2007 (A), 2008 (B), and 2009 (C) for wave-exposed, high-intertidal

347 habitats on the Gulf of St. Lawrence coast of Nova Scotia. Each graph shows the model that best

348 describes the adult-recruit relationship (see Table 1 for model parameters). 


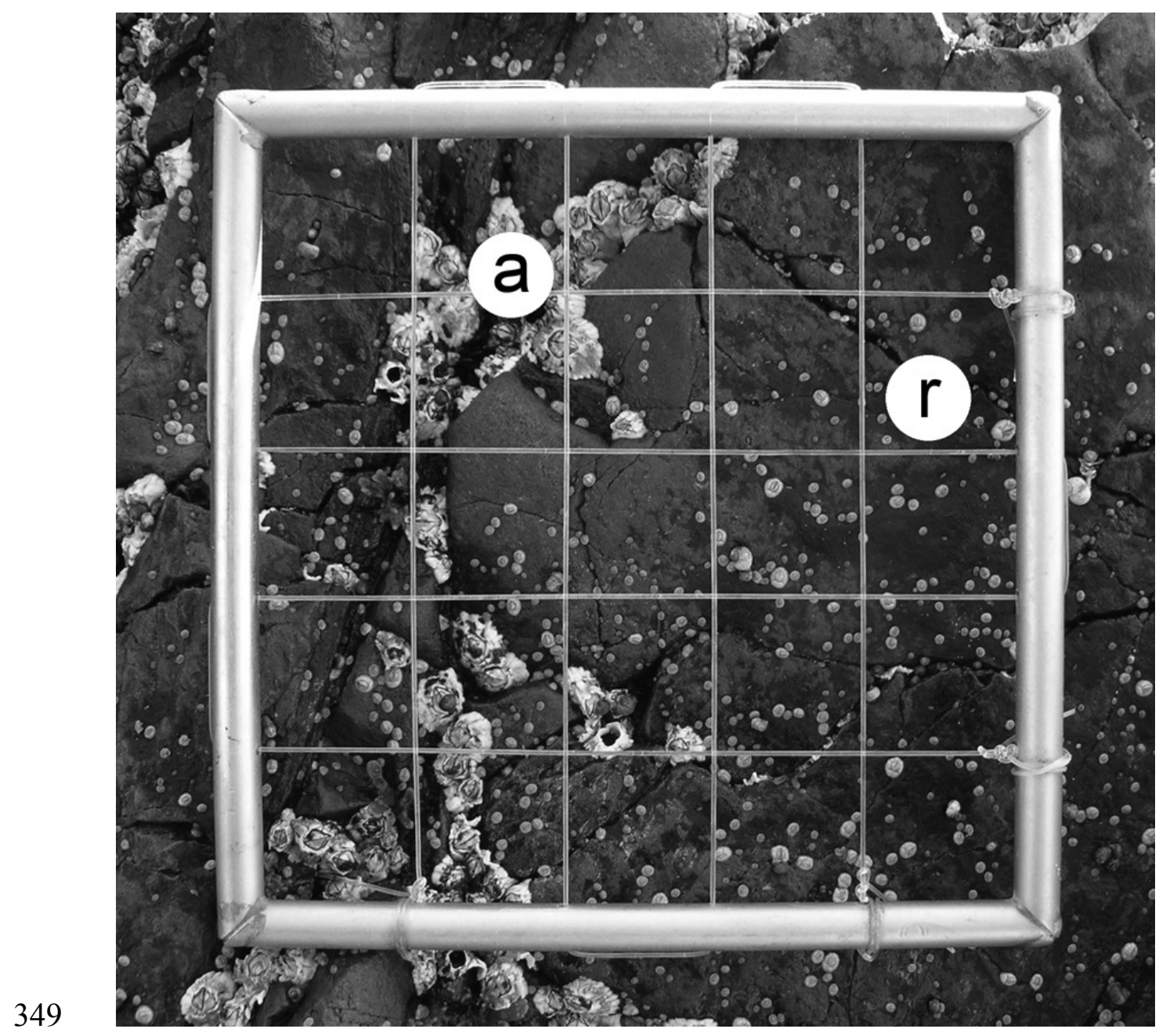

$350 \quad$ Figure 1 


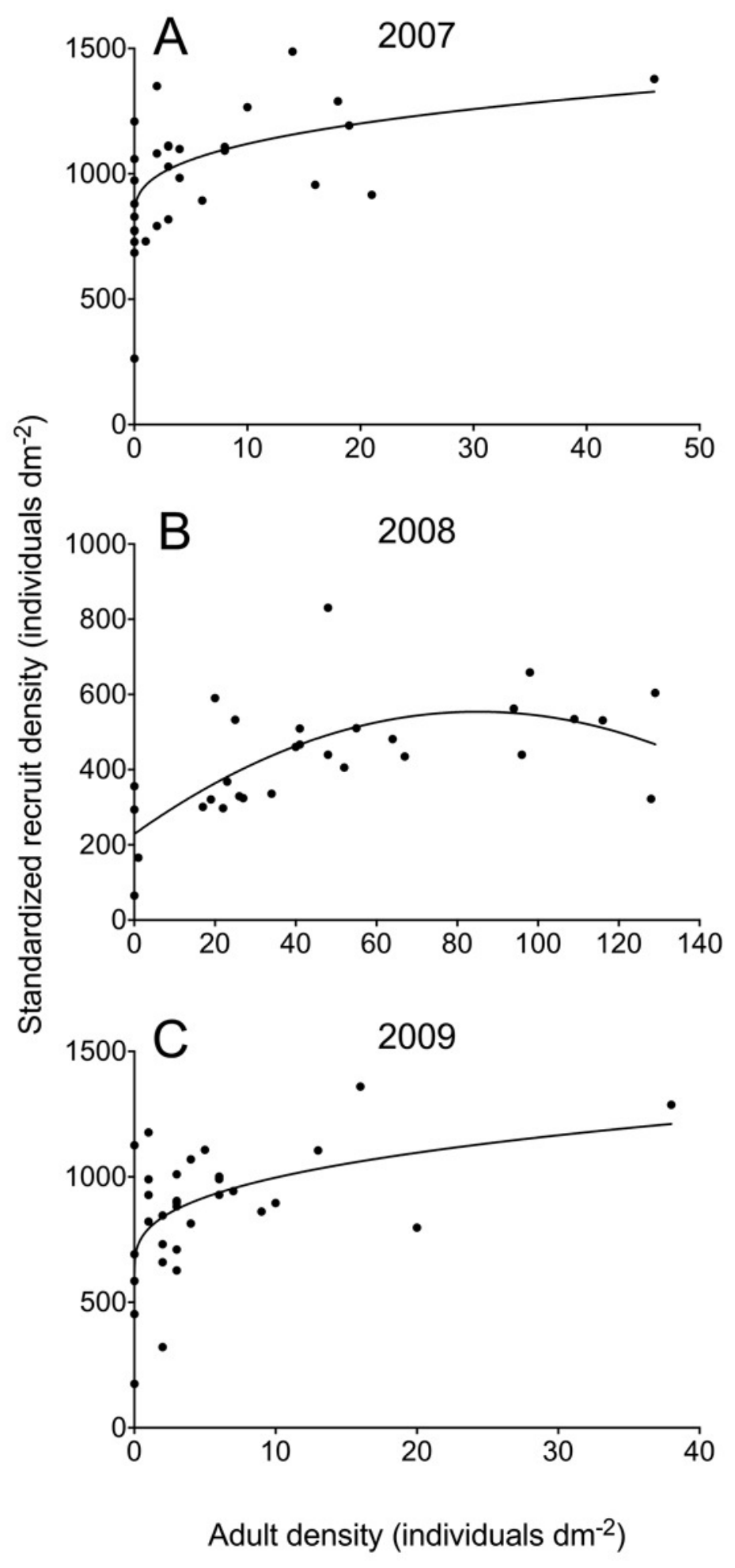

352 Figure 2 